\title{
NOTAS PARA LA CRONOLOGÍA Y COMPOSICIÓN LITERARIA DE LAS VIDAS DE SANTOS DE BERCEO
}

De las tres vidas de santos escritas por Gonzalo de Berceo, las de Santa Oria, San Millán y Santo Domingo de Silos, esta última ocupa lugar central en el desarrollo de su obra y prominente por sus valores de estilo y composición. En las páginas siguientes trataremos de hacer patente esta afirmación mediante un análisis de la estructura y de ciertos procedimientos estilístico-retóricos.

Sabemos por la propia declaración del autor que Santa Oria es obra de vejez (estr. $2 a b)^{1}$ :

Quiero en mj uegez, maguer so ya cansado,

de esta sancta uirgen romançar su dictado...

Y a lo largo del relato, lo confirman observaciones subjetivas que lo muestran cansado y con afán de terminar la labor emprendida $(160 a b)$ :

En esta pleytesia non qujero detardar, sy por bien lo tobierdes quiero uos destaiar.

La voluntad de acabar lo lleva a dar por terminada su obra una primera vez al llegar a la estrofa 184 , en la que pone su nombre como acostumbraba hacerlo al final de sus otras vidas de santos, pero luego reinicia la tarea ${ }^{2}$, y en cambio, cuando la vida se interrumpe defini-

1 Citamos la Vida de Santa Oria por la ed. de C. Carroll Marden, Cuatro poemas de Berceo, Madrid, 1928 ( $R F E$, anejo 9); a la misma ed. nos referimos para las estrofas 1-127 de la Estoria de San Millán (para las estr. 128 ss. nos servimos del texto de la $B A E$, t. 57); y citamos la Vida de Santo Domingo de Silos por la ed. crítica de John D. Fitz-Gerald, Paris, 1904.

2 Véanse las estrofas $184^{-1} 85$ :

Gonçalo li dixieron al uersifficador que en su portaleio fizo esta lauor. Ponga en el su graçia Dios el nuestro sennor, que uea la su gloria en el regno mayor.

Aun non me querria, sennores, espedir; avn fincan cosiellas que uos e de dezir. La obra començada bien la quiero conplir, que non aya njnguno por que me escarnjr. 
tivamente no hay otra despedida formal. Esta aparición del nombre del autor en una aparente terminación, luego rectificada, está en consonancia con la estructura, menos organizada intelectualmente: la Vida de Santa Oria constituye un conjunto indiviso y breve frente a la equilibrada división tripartita de las otras vidas. Internamente, corrobora la posterioridad de Santa Oria con relación a Santo Domingo de Silos el hecho de que entre los milagros de éste figura (estr. 316333) el exorcismo de los demonios que asediaban a la joven Oria recién entrada en clausura, y luego, al iniciar la vida de la santa misma $(6 a b)$, Berceo recuerda a sus asiduos oyentes, más que lectores, que ya antes les ha hablado de ella:

De suso la nonbramos, acordar uos podedes, enparedada era; yazia entre paredes. . ;

y cuando se refiere a su toma de hábito se repiten idénticas palabras en las rimas de las dos vidas (S. Dom., $325 a b c ; S$. Oria, $21 a b)$ :

Entendio el confessor que era aspirada, fizo la con su mano soror toca negrada ${ }^{3}$, fue end apocos dias fecha enparedada...

Desemparo el mundo Oria toca negrada, en vn rencon angosto entro emparedada...

También las Vidas de Santo Domingo y San Millán están estrechamente ligadas, como lo estaban los monasterios y sus santos patronos, y como lo estaba el propio Berceo con la vida religiosa local ${ }^{4}$ : justamente, cuando se cuenta cómo exorcizó Santo Domingo a los diablos que perseguían a Santa Oria (estr. 327-334) y se compara su acción con la de San Millán en casa de Honorio $^{5}$, la última estrofa es un comentario que reúne en un mismo episodio a los tres santos locales y que también parecería señalar la prioridad cronológica de la Estoria de San Millán:

3 Tocanegrada, luego toquinegrada (cf. Libro de Alexandre, ed. R. Willis, Princeton-Paris, 1934, ms. O, 39od', p. 79), es sinónimo de 'monja'. Para este tipo de compuestos formados por un sustantivo que indica una parte del cuerpo o una prenda de vestir seguido de un adjetivo (muchas veces participial), tipo barbiponiente, cf. Leo SPITZER, "El acusativo griego en español", $R F H, 2$ (194o), $35^{-45}$, en especial pp. $4^{0-41}$. Estas formaciones en que todavía no ha aparecido la $-i$ - con la que se fijarán posteriormente, son características del siglo xin.

${ }_{4}^{4}$ En la Vida de Santo Domingo, al recordar a los santos que hicieron vida eremítica, junto a San Juan Bautista, Antonio y Pablo y Santa María Egipcíaca (estr. 55-57), nombra a San Millán y a su maestro San Felices (58-59). Pero el localismo de Berceo es especialmente notable en la Vida de Santa Oria. Respecto al localismo medieval, no incompatible con una formación cultural universalizante en sus manifestaciones más elevadas, cf. Charles H. Haskins, Siudies in mediaeval culture, New York, 1929, cap. 4, "The spread of ideas in the Middle Ages", pp. 92 ss.

5 Comparación que no se halla en la vida latina de Grimaldo seguida por Berceo: Fitz-Gerald, ed, cit., Prefacio, p. xlvii. 
Oymos esso mjsmo de sennor sant Mjllan, que fizo tal mjraglo, yo lo ley de plan, de casa de Honorio segudo vn satan que fazia continençias mas suzias que vn can.

Elementos de estructura y estilo confirman esta presunción. De acuerdo con la técnica del poeta medieval formado en la retórica heredada de la antigüedad clásica, y codificada, comentada, interpretada por sucesivas generaciones desde la edad oscura hasta el siglo $\mathrm{XII}^{6}$, Berceo aplica a sus fuentes latinas el procedimiento de la amplificatio ${ }^{7}$, y si ello es bien visible en la comparación fácilmente realizable entre la Estoria de San Millán y la Vita Sancti Emiliani escrita por San Braulio de Zaragoza en el siglo vu ${ }^{8}$, es más patente si se comparan entre sí las dos vidas de Santo Domingo y San Millán, aquélla de 777 cuartetas de cuaderna vía, ésta de sólo 489 cuartetas ${ }^{9}$.

${ }^{6}$ Edmond Faral, Les arts poétiques du xii et du xiii siècle, Paris, 1924; Edgar de BRuYne, Estudios de estética medieval, Madrid, 1959, t. 1, pp. 231 ss.; t. 2, pp. 9 ss. La presencia de elementos retóricos de la tradición latino-medieval en Berceo fue señalada por ERNST RoBERT CuRTIUs, Literatura europea y Edad Media latina, México, 1955 , t. 1, cap. 5 , y discutida por DÁmaso Alonso, "Berceo y los topoi", en De los siglos oscuros al de oro, Madrid, 1958, pp. 74-85.

7 E. FARAL, op. cit., cap. 2, pp. 61-85; cf. MARía Rosa Lida de MALKiEL, Juan de Mena, poeta del Prerrenacimiento español, México, 1950, pp. 157-196, donde, a propósito del estilo de Mena, se analizan y ejemplifican los procedimientos retóricos en boga durante toda la Edad Media. Procedimientos amplificatorios, aunque diversos, emplea también el autor francés que en el siglo xi versificó la vida de San Alejo, partiendo, como era lo habitual, de un relato latino en prosa: su amplificación tiende a dar relieve a situaciones humanas emotivas y a la exaltación del sentimiento religioso, empleando como principales procedimientos amplificatorios la interpretatio, la expolitio y el apóstrofe (cf. E. R. Curtius, "Zur Interpretation des Alexiusliedes", $Z R P h, 5^{6}, 193^{6}$, en especial pp. 124-131). De la formación cultural de Berceo nada sabemos, pero debió de ser un clérigo con cultura mayor que la media de su tiempo en materia religiosa; el empleo de elementos retóricos en la composición y estilo de su obra señalan su aprovechamiento de la básica enseñanza del trivium y el quadrivium.

8 PL, t. 8o, cols. 699 ss., o en la ed. crít. de Luis Vázquez de Parga, Madrid, 1943. El proceso de amplificación o desarrollo aplicado por los adaptadores o traductores de vidas latinas de santos está determinado, en gran parte, primero por el empleo del verso en lugar de la prosa, con lo cual ya hay una tendencia a formas más elaboradas, especialmente si se usa un metro del tipo de la cuaderna vía; por otra parte, con el paso del tiempo, las distintas versiones romances en verso se van desarrollando y enriqueciendo en episodios o en detalles circunstanciados. La Vie de saint Leger, conservada en un ms. único, el de Clermond-Ferrand, y escrita en el siglo x según opinión unánime de los críticos, alcanza sólo 200 versos y es un relato harto escueto si se lo compara con la $V i e$ de saint Alexis del siglo xI. Los procesos amplificatorios en tomo a las actas de los mártires y la influencia de los procedimientos retóricos en su redacción han sido señalados por Hippolyte Delehaye, Les passions des martyrs et les genres littéraires, Bruxelles, 1921.

9 En una obra medieval, la mayor extensión, dentro de la producción del mismo autor, se ha tomado en cuenta como signo de haber sido compuesta con 
Ante todo, ambas vidas presentan en común una división tripartita perfectamente equilibrada: la primera parte relata la vida del santo, la segunda los milagros hechos en vida y el tránsito de la vida terrena a la de bienaventuranza, la tercera los milagros del santo después de la muerte. Tal división tripartita ${ }^{10}$ no se da en las vidas latinas que con minuciosa sujeción al contenido factual del relato sigue Berceo: la de San Millán, escrita por San Braulio, consta de 21 capítulos, no agrupados entre sí en unidades mayores; la de Santo Domingo, escrita por el abad Grimaldo, tiene divisiones, pero no se corresponden con las adoptadas por Berceo, que subdividió el primer libro de Grimaldo en dos y, en cambio, no parece haber conocido un tercer libro, también con relatos de milagros, de modo que su subdivisión es tan independiente de su fuente como la de la Vida de San Millán con respecto a la suya ${ }^{11}$.

El sentido de esa división tripartita, su valor simbólico, se declara al terminar el libro segundo de La vida de Santo Domingo (estr. 533-535):

Señores e amjgos, Dios sea end laudado, el segundo libriello auemos acauado, queremos començar otro anuestro grado, que sean tres los libros e vno el dictado.

Como son tres personas e vna Deidat, que sean tres los libros, vna certanjdat, los libros que signjfiquen la Sancta Trinjdat, la materia ungada la simple Deidat.

El Padre e el Fijo e el Espiramjento, vn Dios e tres personas, tres sones, vn cimjento,

posterioridad. Entre las distintas obras de Robert Wace, por ejemplo, sus tres poemas religiosos - Vie de saint Nicolas, Vie de sainte Marguerite y Conception de Notre Dame - se consideran anteriores a sus obras profanas "tanto por su brevedad como por su sencillez de estilo", y dentro de las tres mencionadas, al estudiar un especialista los rasgos de estilo que parecen dar prioridad a la Vie de sainte Marguerite, hace notar también que es la más breve (EInAR Ronsjö, "Introduction" a La vie de saint Nicolas par Wace, Lund, I942, p. 20; cf. L. Petit de Julleville, Les mystères, Paris, 188o, t. 1, p. 206).

${ }_{10} \mathrm{E}$. R. Curtius, op cit., excurso 15, "Composición numérica", pp. 7oo-7o3. H. Delehaye, Les légendes hagiographiques, $2^{\mathrm{a}}$ ed., Bruxelles, 19o6, cap. 3 , § 3, p. 110 , da la división tripartita como rasgo característico de las vidas de santos de tipo desarrollado: $I$ ) hechos anteriores al nacimiento del santo (patria, padres, futura grandeza milagrosamente anunciada); 2) vida, virtudes y milagros; 3 ) culto y milagros después de la muerte.

${ }^{11}$ Al contar el último milagro de su Vida de Santo Domingo, Berceo lo deja incompleto (estr. 751-752) "ca fallesçio el libro en qui Io aprendia; / perdio se vn quaderno...", y luego nos asegura que "sy durasse el libro nos avn durariamos". Fitz-Gerald, Prefacio cit., p. Iviii, dice que no se trataría de un cuaderno sino de varios, que formarían "quizá un tercer libro". El primer libro de la vida latina de Grimaldo tenía 20 capítulos y terminaba con el entierro de Santo Domingo, o sea que esa primera subdivisión de la vida latina corresponde al final del libro segundo de la de Berceo (ibid., p. 1). 
singular en natura, plural en cumplimjento, es de todas las cosas fin e començamjento.

Semejante necesidad de puntualización y explicación está de acuerdo con el mayor desarrollo y pausa, con el tempo más lento de La vida de Santo Domingo, y supone una conciencia artística que, si ya presidió la triple subdivisión de San Millán, aquí halla ocasión de expresar todo su sentido y carácter simbólico. Se podría objetar que en una primera obra (Santo Domingo) Berceo explicó el sentido de dicha subdivisión y en una segunda (San Millán) ya no tenía necesidad de hacerlo: creo, sin embargo, que el carácter explícito de estas estrofas está en consonancia con otros elementos de la composición que muestran a Santo Domingo como una amplificación de temas y modos más sucintamente tratados en San Millán, y ya sabemos que el arte medieval es el arte de la amplificatio, no de la abbreviatio. En los comienzos de ambas vidas - comparables por su equilibrio arquitectónico a ciertos grandes trípticos de la pintura religiosa- se presentan hechos semejantes: San Millán y Santo Domingo fueron de niños pastores de ovejas, luego su vocación los llevó a buscar la vida de soledad en el yermo, y justamente esos dos motivos se presentan tratados más esquemáticamente en San Millán. La vida de pastorcillo de San Millán ocupa cuatro estrofas (5-8); la de Santo Domingo, trece. Descontando las coplas 26-32, que sabemos tienen su antecedente en Grimaldo ${ }^{12}$, las restantes nos muestran cómo un mismo autor puede decir las mismas cosas, ampliándolas:

12 Fitz-Gerald, Prefacio cit., p. xliv: "Las coplas 19-26 de Berceo corresponden al pasaje de Grimaldo que comienza con las primeras palabras del cap. II del libro I y que termina con las palabras a iustitia et meritis beatissimi abel protomartiris (ed. Vergara, pp. $3^{1} 5^{-3} 3^{16}$ ). Luego Berceo ha hecho a un lado el parágrafo de Grimaldo, y las coplas 27-31 dan un resumen muy breve del pasaje comprendido entre las palabras Iacob patriarcha pater duodecim patriarcharum... sed iam ad propositi ordinem redeamus (ed. Vergara, pp. 317-322)". Como no tengo la posibilidad de consultar la Vida latina de Grimaldo completa, deduzco de las citas de Fitz-Gerald que, a partir de Abel, se daba una larga lista de pastores (obsérvese que ocupaba las pp. 317-322) de la cual eligió Berceo a David para representar el Antiguo Testamento y pasó luego a Jesucristo y a lo que a él le interesaba sobre todo, el propio santo, realizando esta vez una adecuada abreviación: evidentemente, Berceo consideró demasiado extensa y monótona para su auditorio provinciano la enumeración detallada. Por otra parte, la enumeración de los pastores que desde el Antiguo Testamento se suman para dar especial dignidad a ese modo de vida, frecuente en santos y mártires, es un lugar común hagiográfico, de modo que si Berceo acortó la enumeración de Grimaldo, pudo haber tenido presentes otras enumeraciones del mismo tipo. H. Delehaye, Les passions des martyrs et les genres littéraires, op. cit., pp. 198-200, cita el panegírico de San Mamante escrito por San Basilio: para que no se considere como despreciable el hecho de que fue pastor, se recuerda que también guardaron rebaños Abel, Moisés, Jacob, David, y el propio Jesús, que a sí mismo se designó como "el buen pastor". 
Luego que fue criado que se podio mandar, mandolo yr el padre las ouejas guardar. Obedesçio el fijo, fue luego las curiar con abito qual suelen los pastores usar.

Guardaua bien su grey como muy sabidor, su cayado en la mano a la ley de pastor, bien refiria al lobo e al mal robador; las oueias con elli abian muy grant sauor.

(San Millán, estr. $5^{-6}$ ).

Quando fue peonçillo que se podia mandar, mando lo yr el padre las ouejas guardar; obedesçio el fijo, ca non qujso peccar, jxo con el ganado, pensolo de guiar.

Guiaua su ganado como faz buen pastor, tan bien non lo faria alguno mas mayor, non quería que entrasse en agena lauor: las oueias con elli aujan muy grant sauor.

(Santo Domingo, estr. 19-20).

El notable paralelismo muestra en Santo Domingo cierta tendencia a la expresión menos precisa $(19 c, 20 c)$; luego, las estrofas 21-23 son en realidad desarrollo del último verso de la estrofa $2 \mathrm{o}^{13}$, y la 24 presenta a Dios como pastor $(a, b)$ y como guarda del ganado de Domingo, y termina en un verso paralelo al $6 c$ de la Estoria de San Millan:

El Pastor que no duerme en njnguna sazon, que fizo los auissos que non auen fondon, guardaua el ganado de toda lesion, non fazia mal enello njn lobo njn ladron.

La estrofa siguiente vuelve a insistir en el cuidado que el pastorcillo da a su rebaño, el cual, con la gracia de Dios, mejora cada día. En resumen, el mismo motivo básico permite ver claramente, para Santo Domingo, la ampliación de lo ya dicho más sobriamente para San Millán, y de la gran similitud de palabras y aun de hemistiquios o versos hay que concluir que Berceo, al escribir La vida de Santo Domingo de Silos, tenía muy presente La estoria de sennor Sant Millán

13 En la 21 se dice cómo el santo niño procuraba cumplir con su deber y guardar de daño al ganado, dándole buenos pastos; en la 22 se pondera el cuidado con que las sacaba desde la mañana, cómo marchaba a su lado prudente y atento, sin resguardarse del sol y la lluvia; en la 23, cómo las recogía por la tarde y volvía a la casa paterna como hijo sumiso. 
y fue desarrollando ciertos elementos, sin duda impulsado por un original más extenso y detallado ${ }^{14}$.

Cuando San Millán se acoge al yermo, dice Berceo (estr. 12):

Entendio que el mundo era lleno de enganno, queria partir se delli e fazer se hermjtanno, de leuar non asmaua njn conducho njn panno, fazia se li el dia mas luengo que vn anno.

Luego se dirige a San Felices, escucha su doctrina, y se acoge al yermo. De Santo Domingo, en cambio, dice el poeta que, al ver en derredor suyo la maldad de los hombres, decide acogerse al yermo, pero apoya su decisión en el recuerdo de los muchos padres y santos que hicieron lo mismo, sin olvidar en la enumeración a los propios San Felices y San Millán; esta ejemplificación ocupa las cuartetas 53 a 63: quizá Berceo halló la enumeración en su modelo latino ${ }^{15}$, o quizá el empleo de ese elemento amplificativo le fue sugerido por la previa enumeración de los pastores. Me inclino a la segunda conjetura porque en este lugar del San Millán Berceo emplea también una amplificación retórica que no se hallaba en la Vita Sancti Emiliani ${ }^{16}$, y si bien es cierto que no pocas veces versos enteros pasan de una obra a otra, no lo es menos que Berceo, artista muy consciente, reemplaza su hermosa descripción del yermo al que se retiró San Millán ${ }^{17}$ (uno

14 Sin embargo, una correspondencia como la de pastor de ovejas y pastor de almas, que se hace en la Vita de San Braulio, cap. 8 ("futurus pastor hominum erat pastor ouium...", etc.), no se recoge en la Vida de San Millán, quizá por ser una sencilla alusión al pasar, y en cambio se desarrolla en Santo Domingo por existir un original en el que el motivo se extiende largamente. C. Guerrieri Crocertr, Gonzalo de Berceo, Brescia, 1947, p. 13, señala que, en general, Berceo no sigue a ojos cerrados sus fuentes latinas: las subordina a sus intereses, dando relieve a lo que atrae a su fantasía, suprimiendo o dejando en la sombra lo que no le interesa, dando nuevo significado y haciendo resaltar ciertos detalles que son casi incidentales en el texto latino.

15 En la edición de la Vita de Grimaldo que utilizó Fitz-Gerald para su confrontación de fuentes hay aquí unos puntos suspensivos, y como Berceo amplificó cinco renglones del texto en 24 estrofas (50-73), habría aquí "en el ms. del que se sirvió Vergara una laguna bastante grande que no se encontraría en el ms. del que se sirvió Berceo" (ed. cit., Prefacio, p. xliv).

${ }_{16}$ Cap. 11: "Celsiora petit leuesque per ardua gressus agebat spiritus promptus ut non solum corde sed etiam corpore, plorationis ualle gradiens, de uirtute in uirtutem uideretur Iacob quodammodo scalam conscendere".

17 Berceo se detiene morosamente en la descripción del abrupto lugar elegido, de las fieras bestias cuya compañía, sin embargo, prefiere el santo a la de los hombres; y si bien alude a la busca de lugares más altos y alejados, no la presenta solamente, como en la Vita latina, a modo de una escala de perfección. El elemento descriptivo (estr. $27,28,30,31,42,49$ ) se va enlazando al relato de penitencias, rezos, abstinencias, etc., en un conjunto de más de 80 versos: no hay que olvidar que los tratadistas retóricos de los siglos xn y xIII dan lugar importante a la descripción, hasta el punto de que ésta es para Mathieu de Vendóme el objeto supremo de la poesía (E. Faral, op. cit., 
de los trozos retóricos más hermosos de la Estoria de San Millán) por la enumeración ejemplificadora tan cara a la Edad Media.

Volviendo a las divisiones internas que Berceo señaló en sus $V i$ das, el final de cada parte se considera como un descanso o interrupción, pero se anuncia la continuación de la obra: esos anuncios, paralelos a las estrofas introductorias y finales, constituyen los que llamaremos elementos de encuadre. Todo ese material externo al relato de la vida del santo en sí es más rico en Santo Domingo que en San Millán, no sólo por el número de versos que ocupa, por su extensión, sino por su carácter explícito que se ofrece al lector en consonancia con la explicación de la división tripartita ya analizada, como rasgo de un arte muy consciente del valor y significación de sus elementos formales.

La estoria de San Millán tiene dos estrofas introductorias (1-2) y una de finalización del "Libro primero". El "Libro segundo" tiene dos estrofas introductorias ( $109-110)$ y una de encuadre final (320); el "Libro tercero", una estrofa de encabezamiento ( 321 ) y una de cierre $(489)$ en la que el autor da a conocer su nombre, lugar de nacimiento y formación.

La Vida de Santo Domingo se inicia con cuatro estrofas introductorias (en la segunda de las cuales nos da Berceo el cómo y el porqué de su obra en romance) y termina con una estrofa de cierre (288); el "Libro segundo" comienza con una estrofa de iniciación y termina con tres (las que explican el sentido de la tripartición: 533-535); el "Libro tercero" tiene una estrofa introductoria (536) y termina con una digresión de 24 estrofas $(754-777)^{18}$.

Ese desarrollo de los elementos enmarcadores que señalan lo ex-

pp. 75 ss.). Pero, además, Berceo conocía sin duda la Vita sancti Pauli eremitae de San Jerónimo (en la estr. $5^{6}$ de Santo Domingo se menciona a Pablo junto a Antonio en términos que la recuerdan), con sus cuevas, montes y animales salvajes; de San Jerónimo puede proceder el sentido simbólico con que esos elementos se revisten en la fraseología de la ejemplaridad y la lucha con el demonio, por ejemplo, cuando San Antonio encuentra a San Pablo en su cueva (cap. 9): "Scio me non mereri consceptum tuum: tamen nisi videro, non recedam. Qui bestias recipis, hominem cur repellis" (PL, t. 29: cf. San Millán, estr. 45). También en ia Vita sancti Hilarionis eremitae se extiende San Jerónimo en la descripción del lugar alejado y abrupto que el santo busca como objetivación del perfeccionamiento interior. Parecería obvio que en una primera vida de santo recordara Berceo las tan conocidas de San Jerónimo.

18 Los modos de comenzar y terminar una obra estaban también regulados en las poéticas medievales: para la terminación se prefería el enunciado de una idea general o el agradecimiento a la divinidad inspiradora (E. FARAL, op. cit., pp. 59-6o). Este último tipo es el que sigue Berceo, pues se adapta al contenido y finalidad de las vidas de santos: que el santo interceda para que Dios perdone al autor, o a los hombres en general, tal es el contenido de la larga digresión final de la Vida de Santo Domingo, en tanto que la de San Millán sólo la termina dando su nombre, condición, etc., o sea otro de los modos de señalar la terminación de una obra. 
terior, lo puramente arquitectónico, tiene su paralelo en la forma de sucederse los milagros mismos de cada santo. En las narraciones de Berceo hay tres medios formales para la presentación y desenvolvimiento del relato, que he llamado encuadre ${ }^{19}$, transición y enlace.

El encuadre pone en relación al autor, la materia de la obra y el público (oyente o lector). Así en San Millán, estr. 362, y en Santo Domingo, estr. 644:

Sennores, la façienda del confessor onrado non la podrie contar nin romanz nin dictado, mas destaiarvos la quiero, hir a lo mas granado, quando gano los votos, commo ovo lidiado...

Vn preçioso mjraglo uos queremos dezir, deuedes aoyrlo las oreias abrir, de firme uoluntad lo deuedes oyr, veredes al buen Padre en grant preçio sobir...

La transición va señalando entre los milagros la línea misma de la vida del santo o comentando su carácter y virtudes. Así en San Millán, estr. 122, y en Santo Domingo, estr. 537:

Fuyo e desterrosse a la tierra estranna, el confessor preçioso finco en su montanna. Mientre el mundo sea et durare Espanna sjempre sera contada esta buena fazanna...

Desque sancto Domjngo fue dest sieglo passado, fazia Dios por el tanto que non seria asmado: vinjan tantos emfermos que farian grand fonsado, non podriamos los medios nos meter en ditado...

El enlace o encadenamiento está representado por fórmulas que puntualizan el paso de un episodio a otro que supone un corte en el relato, o el cambio de protagonista. Naturalmente sólo de vez en cuando se utiliza el enlace o encadenamiento en las vidas de santos de estructura lineal, con protagonista único: en la Vida de Santo Domingo, estr. 119, 186, se pasa de un episodio a otro con la fórmula habitual:

Dexemos al buen omne folgar ensu posada, ministrar alos pobres elli con su mesnada; demos al monasterio de sant Mjllan tornada, que avn non es toda la cosa recabdada. . . 20

19 E. R. Curtius, art. cit. sobre La vie de saint Alexis, pp. 117-118, llama "encuadre del relato" ("Die Einrahmung der Erzählung") a los elementos extraños al relato mismo de la vida y que alli son simplemente el exordium y la conclusio, que sólo ocupan dos estrofas. Los términos elegidos por mí para este análisis lo han sido con total independencia respecto de los de Curtius.

20 Es el tipo de fórmula que se halla en toda la literatura en prosa y en verso de la Edad Media y que nos sale al paso continuamente en el Poema de 
Dexemos al bon omne con el rey afolgar, conujene nos vn poco la materia a cambiar, non podriamos sin esso la razon acordar, por que nos alonguemos bien sabremos tornar'21.

Encuadre y transición son los nexos que Fitz-Gerald (Prefacio cit., p. Iviii), al comparar Santo Domingo con su fuente latina, califica de "coplas de transition et de remplissage", o sea "ce que nous pouvons appeler articulation du récit". Creo que vale la pena deslindar en el conjunto de los relatos el carácter y contenido de esas coplas "de relleno y transición", según la calificación un poco despectiva del editor de La vida de Santo Domingo de Silos, para poder valorar el arte de la composición en Berceo. La utilización del encuadre está más desarrollada en Santo Domingo que en San Millán: en los libros II y III de éste, fuera de los encuadres iniciales y finales, sólo hay otros dos, que jalonan episodios importantes, uno en el libro II (estr. 199), que marca el comienzo del relato del triunfo del santo contra los demonios que querían tomar venganza por las muchas derrotas que de él habían sufrido, y el otro el que en el libro III precede a la ganancia de los votos (estr. 362). En San Millán lo habitual es que los milagros se sucedan unos a otros sin interrupción alguna, o simplemente como en 1 32ab: "Entre los sos milagros en el terçer lugar / de una paralitica vos queremos fablar", o el verso final del milagro (y último de la estrofa de cuaderna vía) es de loor del santo $(176 d)^{22}$. En cuanto a los elementos de transición, no siempre tienen carácter claramente distintivo, y muchas veces quedan involucrados en el relato del milagro mismo: este tipo de transiciones que podríamos llamar indefinidas es más frecuente en San Millán, y no sólo en términos relativos: constituye un elemento diferenciador que se une a los ya señalados, y revela en la composición de Santo Domingo una mayor preocupación por la sistematización de la materia poética como consecuencia de una conciencia artística ya muy segura de sus medios expresivos,

Alfonso XI, por ejemplo (dexemos... fablemos, dexar... fablar, dexaré... contaré, dexaré... fablaré), importante en Santa Maria Egipciaca, v. 798 , con su doble aspecto de exaltación de la vida monacal y la eremítica ("Fuelgue vn poco Maria: / contar vos e de huna abadia...") y que tiene su equivalente en relatos franceses, por ejemplo en Aucassin et Nicolette, xxxvi ("Or lirons d'Aucassin, si dirons de Nicolete"). No había en los tratados de retórica mayores detalles acerca de los modos de encadenar el relato (E. Faral, op. cit., cap. 2, p. 6o).

21 Hay aquí una nota muy personal, casi confidencial (cf. Américo Castro, La realidad histórica de España, México, 1954, pp. 341-350): casi asistimos al planteamiento de los problemas de la construcción artística que se le presentan al "versificador".

22 Otras veces el loor del santo es una exclamación dentro del relato mismo, por ejemplo en $\mathbf{I}_{5} \mathbf{2 d}$, de modo que no constituye una línea de demarcación: forma parte del elogio del santo como mira constante de la composición total y de cada uno de sus elementos integrantes. 
con la diferenciación e integración de los elementos del relato (milagros por un lado, elogios del santo mismo por otro) frente a una mayor flexibilidad de composición en la obra juvenil.

En cambio, en Santo Domingo de Silos, el libro II se inicia con una serie de milagros de relato pormenorizado (entre quince y veinte cuartetas, alguno de sólo seis) separados por una estrofa completa de encuadre; después de ese grupo inicial así estructurado (cada milagro destacado como una miniatura enmarcada), el encuadre reaparece hacia el final del libro con el mismo carácter de separador de milagros importantes. Esos encuadres, pausas menores comparadas con las pausas mayores al final de cada uno de los libros, insisten en el carácter notable de los milagros (bello, sabroso de oír), o en su número, casi incontable ${ }^{23}$. El libro III presenta en cambio gran número de milagros, contados con ritmo rápido, sin encuadre ni transición ${ }^{24}$. Hacia el final del libro III reaparecen los encuadres precediendo a milagros

23 Cf. Santo Domingo, estr. $315,335,351,384$ :

Señores, sim quisierdes vn poquiello soffrir, non querria con esto de uos me espedir, de un otro mjraglo uos querria dezir, por amor del buen Padre deuedes lo oyr...

Vn otro bel miraglo uos querria dezir, que fizo este confessor, sabroso de oyr, maguer uos enoyedes, deuedes nos soffrir, voz dizredes que era bueno de escriujr...

Muchos son los mjraglos que dest Padre sabemos, los vnos que oymos, los otros que leemos, endubda nos paramos en qual començaremos, mas aqual parte que sea a deujar abremos...

Todos los sus mjraglos, ¿quj los podria contar? nolis dariamos cabo, njn abriamos uagar: enlos que son contados lo podedes asmar, de qual merito era el baron de prestar.

He elegido entre varios este último por su semejanza con las ponderaciones de los muchos milagros que hizo San Nicolás, según se lee en su vida versificada por Wace en el siglo xn (vs. 195 ss., 601 ss.):

Gref me serreit a raconter et gref a vus a esculter les granz miracles et les bens qu'il fist a plusurs cristiens. . .

Longe chose serreit a dire et mult ennuose a escrivre les miracles et les socurs que li $\operatorname{seinz}$ hom fist a plusurs.

Pero en el relato de Wace, obra de estructura muy poco trabada comparada con las de Berceo, este encuadre de introducción a milagros es lo excepcional.

24 Justamente, la falta de encuadre y transición contribuye a la impresión que el lector recibe de hallarse ante una serie innumerable: los incontables milagros que el santo continúa obrando después de su muerte. 
de tipo especial y muy significativos para la fama del santo: la redención de cautivos. Los milagros no separados por encuadre se suceden directamente, una veces engarzados con notable habilidad ${ }^{25}$, otras veces sin ningún nexo, o relacionados por los que hemos llamado elementos de transición, no siempre aislados del encuadre, sino en sucesión o superposición: esto ocurre en la terminación de la Estoria de San Millán, con esa peculiarísima nota personal no derivada de las fuentes latinas. Dos campanitas penden del altar y cuando ha de ocurrir algo extraordinario tañen por sí solas -y Berceo las ha oído (estr. 487 ):

Assi pueda la gloria del Criador aver commo por mis oreias las oy yo tanner...

Y luego la nota de transición que prepara el encuadre formal con que termina el libro III y la Vida de San Millán (estr. 488):

Muchas otras noblezas de preçio muy mayor cunteçen en la casa del sancto confessor:

Dios por la sue sancta graçia nos de la sue amor, el libro es complido, graçias al Criador.

Gonzalvo fue so nomne qui fizo est tractado...

También en Santo Domingo, antes de contar un milagro importante hay sucesión de los dos elementos articulatorios ${ }^{26}$. Entre los elementos de encuadre y transición aparecen asimismo elementos de comentario en relación con los materiales que se recogen: ya sabemos cómo Berceo, con su reverencia de intelectual medieval por la letra escrita, se somete a sus fuentes sin apartarse de ellas, pues lo que "yace en escripto" representa la verdad, la seguridad incuestionable por encima de toda duda o discusión, pero se permite hacerlas a un lado en detalles que tienen algo de infantil o de humorístico, v. gr. en Santo Domingo, estr. 613:

25 Santo Domingo, estr. 571: "En essi dia mesmo que esta guarescio / alunbro y vn çiego..."; estr. 578: "En Agosin moraua otra que non uedia..."; estr. 597: "Auja otro contrecho que non podia andar..."; estr. 626: "La çiega alunbrada e yda su carrera, / vino vn demonjado, de Çelleruelo era..."; San Millán, estr. 1 13: "En essa misme tierra, dessa penna real / avie vna contrecha..."; estr. 157: "Luego que ovo esto sant Millan recadado, / adussieron un clerigo del demonio damnado..."; estr. 169: "Aduxieronli luego otro demoniado..."

26 Santo Domingo, estr. 731-732:

Quj quiera que lo diga o muger o uaron, que el Padron de Silos non saca Jnfançon, repienda se del dicho, ca non dize razon, denuesta al buen confessor resçibra mal galardon.

Aun por que entiendan que non dize derecho, qujero juntar a este otro tal mesmo fecho, de otro cauallero... 
Sy queredes del nonbre dela dueña sauer,

Orfresa la clamauan, deuedes lo creer; non quisiemos la ujlla en escripto meter ca non es nomneciello de muy buen paresçer,

o justifica una omisión achacándola a la mala letra y a la dificultad de la lengua ${ }^{27}$. Pero sabemos ya que su sujeción a la fuente escrita lo es en realidad al contenido básico de hechos; se siente cronista en romance de verdades de antaño conocidas y reverenciadas en la lengua docta, pero a pesar de esas declaraciones de que no escribe en latín porque no tiene ciencia para hacerlo o de que una parte de la historia no pudo entenderla por las letras y porque era "ençerrado latino", acomoda sus fuentes sometiéndolas a las amplificaciones, variaciones, etc. que su aprendizaje de "clerecía" le señalaba como más adecuadas a sus fines. Si el análisis de las dos vidas de santos no bastara para mostrarlo como un artista muy consciente de su tradición y oficio, ello resultaría palmario con el análisis de otros recursos de composición y estilo, tales como el modo de desarrollar un milagro de tipo corriente - la cura del paralítico- o el empleo que hace de uno de los tropos recomendados por la retórica medieval: la perifrasis $^{28}$.

Berceo utiliza como procedimiento artístico regular la designación casi constante del protagonista por medio de perífrasis ${ }^{29}$, y tam-

27 Santo Domingo, estr. 6og:

Caetio y vn çiego, de qual parte que uino, non departe la ujlla muy bien el pergamjno, ca era mala letra, ençerrado latino, entender non lo pudi, por Señor Sant Martino.

28 Algunos tratadistas la llaman también circuitio; tiene como característica la eliminación del término propio para designar un objeto y su sustitución por una, o más frecuentemente, varias palabras equivalentes a aquél. E. Faral, op. cit., p. go, destaca el valor del estudio de este y otros tropos como "el capítulo más importante de la historia del vocabulario poético en la Edad Media". Por otra parte, ya en los escritos hagiográficos de los primeros siglos es patente la huella de la retórica de los sofistas, de quienes tomaron los escritores cristianos los caracteres del panegírico, germen literario de las vidas de mártires y santos (Cf. H. Delehaye, Les passions des martyrs. .., cap. 3, pp. 183235).

${ }_{20}$ En la Vie de saint Nicholas de Robert Wace, ya bastante desarrollada, si bien es casi un siglo anterior a Berceo (se la sitúa hacia 1150), se nombra al santo exclusivamente por su nombre. En el ms. que sigue Einar Ronsjö (ed. cit.) se usa únicamente 'Nicolás', 'San Nicolás'; en el v. 791, "De seint Nicholas le baron"; en el v. 1486, "li ber" = 'le baron'; en el v. 604, "li seinz hom"; pero en el último milagro, que para llenar una laguna del códice elegido para la edición ha sido tomado de otro, se dice, v. 1539, "Li bons confessour le seignat", y en algunos casos en que el ms. elegido dice '(San) Nicolás', otros dan 'el santo' (vs. 121, 274, 697, 1084, 1154; 'el santo hombre', v. 36o). Este tipo de designación para el protagonista se parece más al que usa el anónimo tras- 
bién hay aquí diferencias entre San Millán y Santo Domingo ${ }^{30}$ : si bien las perífrasis complejas, de un verso alejandrino completo o más, son algo más ricas en el libro III de San Millán que en el correspondiente de Santo Domingo, las fórmulas más breves (sustantivo y adjetivo) son más significativas, menos obvias en éste. Por otra parte, la utilización de esas perífrasis, sobre todo en el primer verso del cuarteto, con valor de sujeto, es algo menor en Santo Domingo, lo cual implica mayor dominio técnico del relato, ya que el artista consigue llevar adelante su exposición sin recurrir tan constantemente a la mención perifrástica expresa del sujeto de su obra.

Comparando el libro I de la Estoria de san Millán, 108 estrofas, con el mismo número de estrofas en Santo Domingo, encontramos la siguiente situación que aclara lo ya expuesto:

San Millán

San Millán: 1

Perífrasis: 32

sust. y adj. (tipo vir beatus):

sancto confessor: 2

omne benedicto: 2

omne bono: 4

santo omne: 4

otras combinaciones: 11

Perífrasis complejas ${ }^{31}: 6$
Santo Domingo

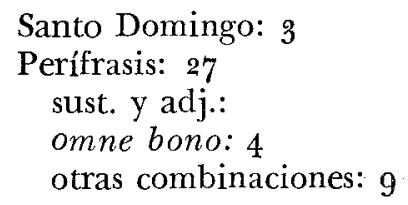

Perífrasis complejas ${ }^{32}: 7$

ladador de la Vida de Santa Maria Egipciaca, en la que a la santa se Ia llama siempre por su nombre o con el pronombre personal correspondiente (pocas excepciones: v. 181 la cativa; v. 404 la mezquina; v. 1136 la santa; v. 1175 la duenya; v. 1339 esta duenya), en tanto que Sózimas se presenta diez veces como "el santo omne", una "el omne santo", v. 10o8, otra "el buen varón", v. 1393. (Las citas corresponden a la ed. de R. Foulché-Delbosc, Textos Castellanos Antiguos, I, Barcelona, 19\%7).

${ }_{30}$ Perífrasis, menos en número y de menor desarrollo, hay en la Vita $S$. Emiliani de San Braulio: beatus uir, beatissimus uir, caelestis uir, sanctus uir, sanctus homo, uir iste sanctus, homo bonus, homo Dei, uir Dei, uir Dei egregius, seruus Christi, seruus Dei, dilectus Dei, sanctus Dei. Son perifrasis simples de sustantivo y adjetivo o un sustantivo (o adjetivo) seguido del genitivo Dei. Algo más variadas serían las del modelo latino de Sto. Dom., según las que he podido entresacar de los extractos de Fitz-Gerald, pero nada se puede decir de la frecuencia de su uso a través de tan magro testimonio: beatus vir, vir beatus, beatus Dominicus, beatus confessor, confessor Domini Dominicus, servus (y famulus) Domini Dominicus, sanctus vir, vir venerabilis, vir Dei.

${ }^{31}$ Las perífrasis complejas tienen un núcleo de sustantivo, modificado por adjetivo y seguido de un complemento: $39 a b$ "El baron acabado de cunplida uondat, / ançiano de seso, mançebo de edat"; 48 " "EI baron esforçađo de la sancta creençia"; $54 a$ "El buen sieruo de Christo..."; $62 a$ "...el omne bueno en hora buena nado"; $69 c$ "... del su sieruo de preçiosa ujda"; $106 a$ "El preste benedicto, saçerdot derechero".

32 Entre las más extensas aparece un tipo que sólo excepcionalmente se da en San Millán: las determinaciones yuxtapuestas como parte de la perifrasis: 
Si comparamos los libros II de ambas vidas, con su paralelismo casi total de estructura ${ }^{33}$ (pues se trata de los milagros hechos en vida), la situación es la siguiente:

$$
\begin{gathered}
\text { San Millán } \\
\text { (212 cuartetas) }
\end{gathered}
$$

San Millán: 14

designación con un sust.: 6

perífrasis de sust. y adj.: 59

omne bueno: 20

sancto omne: 8

confessor precioso: 8

confessor honrado: 2

\author{
Santo Domingo \\ (247 cuartetas)
}

Santo Domingo: 3

designación con un sust.: 9

perífrasis de sust. y adj.: 66

perífrasis con el sust. padre: 23

padre santo: 8

padre bueno: 6

padre bendito: 3

padre piadoso: 2

padre cordoioso: 2

padre verdadero: 1

perifrasis con confessor: 14

De esta confrontación, lo más sugerente es hallar en Santo Domingo cierta preferencia por formas designativas, y el que en el uso de perífrasis de sustantivo y adjetivo, las más frecuentes pertenecen a tipos menos obvios o menos gastados y desdibujados que en San Millán: padre, confessor, frente a hombre ${ }^{34}$. Además, entre las perífrasis breves, hay algunas creaciones de interés: $304 a$ "el ambiso baron" "35, $437 a$ "el baron adonado", $44^{1} a$ "el adalit caboso"36, $443 c$ "el donoso sennor", $478 a$ "el buen Mjssa cantano", $5^{24} b$ "tan preçioso Frayre".

$34 a$ "el sancto pastorçiello, niño de buenas mañas"; $86 a$ "sennor Sancto Domjngo, leal escapulado"; 7 oc "el buen Christiano, sucessor de Elias" (Elías aparece mencionado en el cap. 4 de la Vita de Grimaldo, que corresponde a esta estrofa 7o, pero no se puede saber con qué valor sintáctico o estilístico: FrrzGerald, p. xliv). Son también más frecuentes las construcciones de relativo. Entre las perífrasis más sencillas en Santo Domingo hay menos de las formadas por sustantivo y adjetivo, pero aun las designaciones y perífrasis más corrientes suelen acompañarse de formas de intensificación afectiva (tan, tal).

${ }^{33}$ En realidad, las comparaciones hechas con los libros I no responden a una equivalencia perfecta, pues 109 estrofas de San Millán cubren el desarrollo total de la vida, en tanto que el mismo número de cuartetas en Santo Domingo sólo nos llevan al momento en que por envidia de otros monjes y como para probar su santidad es enviado el santo a una pobre iglesia subsidiaria del monasterio de San Millán, o sea que no se ha llegado aún al momento de su paso a Castilla y sus trabajos de engrandecimiento de Silos.

34 Quizá habría que tener en cuenta en la preferencia tan marcada por padre razones de tipo personal y afectivo antes que de orden artístico.

35 Ambiso 'bueno, noble, prudente' (cf. el "Glosario" de la ed. cit. de FitzGerald).

${ }^{36}$ El epíteto caboso se aplica en $58 b$ a San Millán ("San Millan el caboso"): en su propia Vida, 123a, se le designa también como "el buen campeador". Entre las perífrasis más originales o más significativas de este tipo en el libro II de San Millán sólo hallo, además, "el buen emparedado", $144 a$. 
En cambio, en el libro II de San Millán las perífrasis extensas de tipo desarrollado son tan ricas e imaginativas como las de Santo Domingo, y algo más frecuentes ${ }^{37}$. De este análisis, quizá el hecho significativo sea el que Berceo, en Santo Domingo, no ha usado las perífrasis más comunes (que se encuentran ya en las vidas latinas) y ha preferido las de núcleo sustantivo menos vacío de significación y más adecuado a la condición (real o sentida) del santo mismo, y ello constituiría otro rasgo de madurez que se une a los ya analizados, si bien la utilización del tropo prueba la regularidad ("renglones como surcos en pardas sementeras...") de la composición en nuestro autor.

Tres veces ha contado Berceo el milagro de la cura de la parálisis, lugar común de las vidas de santos ${ }^{38}$ : Estoria de San Millán, estr. 132137; Vida de Santo Domingo de Silos, estr. 290-314 y 581-59o. El más extenso alcanza veinticinco cuartetas y el más breve, lógicamente, es el de San Millán; para uno de los obrados por Santo Domingo, Berceo amplió, como ya lo vimos con otros motivos comunes a las dos vidas, su propia redacción anterior.

\section{San Millán}

De una paralitica vos queremos fablar: / toda era tollida, non se podie mandar; / iazie alechigada, ca non podie andar $\left(13_{2} b-d\right)$; iazie la mesquiniella... (134c); prisieron esta duenna enferma los parientes, /

\section{Santo Domingo}

De otra ${ }^{39}$ paralitica uos queremos contar, / que non auja poder de sus mjenbros mandar $\left(5^{81} a b\right)$; non andaria enpiedes. . $\left(5^{82 a}\right)$; odie la mezquinjella... (584a); Presieron la los omnes aquj dolia su mal..., /

37 San Millan: $129 a$ "el omne benedicto pleno de santidad"; $174^{a}$ "al confessor natural de Berceo"; $186 c$ "el cuerpo sancto patrón del territorio"; $198 \mathrm{c}$ "el benedicto preste de preçiosa vida"; $200 a$ "el padre de la grand sanctidad"; $222 a$ "el confessor preçioso siervo del Criador"; $246 a$ "Padre de los mezquinos el varon esforzado"; 266 a "el varon benedicto de la vida lazrada"; $271 a$ "el confessor preçioso de la voluntad larga"; $279 a$ "el varon acabado que Dios mucho amaba"; 294a "el cuerpo benedicto propheta verdadero"; $298 a$ "el confessor preçioso siempre bien acordado". Santo Domingo: 29ga "el confessor preçioso de los fechos cabdales"; $368 a$ "el padre de la grant sanctidad"; $373^{a}$ "sennor sancto Domjngo, conplido de bondat"; $375^{a}$ "dest confessor tan sancto, de tan alta fazienda"; $4^{\circ} 5^{a}$ "el confessor caboso lleno de caridat"; $428 a$ "padre de buen tiento e de buen conosçer"; $433^{a}$ "sennor sancto Domingo, lumbre delos perlados"; $479 a$ "sennor sancto Domingo, padre delos claustreros".

${ }_{38} \mathrm{H}$. Delehaye, Les légendes hagiographiques, op. cit., cap. 3, § 3, p. 111: "Et comme c'est surtout par les miracles que Dieu manifeste les mérites de ses serviteurs, on peut être sûr que le saint, quel qu'il soit, a guéri des aveugles, fait marcher des paralytiques, chassé des démons, et ainsi de suite". Por ejemplo, en la Vie de saint Nicolas de Robert Wace hay también un paralítico curado y, lógicamente, en la descripción de la enfermedad y su cura hay entre ésta y las tres descritas por Berceo, notas comunes.

${ }^{39} \mathrm{El}$ otra se refiere al milagro contado con anterioridad, estr. 290-314, o más probablemente al hecho de que también es una mujer, aunque ciega, la protagonista del milagro contado inmediatamente antes. 
levaronla al preste de las mannas valientes... (193bc); Fue puesta a la puerta la enferma lazdrada (134a). fueron paral sepulcro del confessor cabdal $(585 a c)$; Leuaron la enferma al sepulcro glorioso..., / pusieron la delante al padre prodigioso $\left(5^{86 a c}\right)^{40}$.

Aunque no disponemos de la fuente latina completa para el episodio, podemos deducir, de lo que transcribe Fitz-Gerald en el Prefacio y de la comparación con la Estoria de San Millán y su fuente latina, ciertas conclusiones:

I) Berceo amplifica aquí con evidente progreso artístico el tipo de relato que ya había hecho en San Millán: se detiene en la descripción de la enfermedad con comparaciones sugerentes y adecuadas que reemplazan expresiones pobres:

San Millán: Toda era tollida, non se podie mandar (132c); Iazie alechigada, ca non podie andar (132d); la enferma lazdrada (134a). del mal e del lazerio sedie muy crebrantada (134b); vio esta enferma de vida desesperada $\left(135^{b}\right)$; fue quita la enferma de la tribulation / tornose a sue casa sana sin lesion (136cd).

Las notas más expresivas correspoden a $134 \mathrm{~cd}$, "Iazie la mesquiniella en tierra abuzada, / ca non podie erecha levantarse por nada", muy por debajo de la expresividad lograda en los relatos de Santo Domingo:

non andaria enpiedes njn prendrie delas manos, / qui la fiziesse dueña de Moros e Christianos (582ab); los huessos auja solos cubiertos del pelleio $\left(5^{8} 3^{b}\right)$; yazia ella ganjendo como gato sarnoso $\left(5^{86 d}\right)$; que yazia en tal pena auja muchos veranos, / avienna deleyda los dolores cutianos ${ }^{41}\left(5^{82 c d)}\right.$; domjngos e cutianos lazraua enpareio $\left(5^{8} 3 c\right)$.

2) Las pocas líneas que conocemos del original latino (FitzGERALD, p. lii) nos permiten apreciar su independencia en el detalle

40 La otra cura de paralítica en la Vida de Santo Domingo de Silos no tiene contactos con la de San Millán, salvo en dos versos que no pasan de ser lugar común: "Leuaron la aSilos, la enferma lazrada, / fue delante la puerta del confessor echada" (298ab).

41 A pesar de que en la fuente seguida por Berceo para la Estoria, San Braulio dice que Bárbara de Amaya había perdido la salud hacia tiempo (dudum), el detalle no es recogido por el romanceador: "Nomine autem Barbara, mulier quaedam a finibus Amaiae abducta, paralisi morbo contracta atque uehementer uexata, salute dudum amissae eius sancti oratione est restituta". No conocemos la fuente del episodio de Santo Domingo, pero la expresión en romance adquiere resonancia poética, al evocar Berceo el momento en que, en medio de la alegría de la naturaleza, sería más doloroso para la enferma la imposibilidad de moverse: "que yazia en tal pena auja muchos veranos" (582c). 
y en el aprovechamiento de una fuente ya pormenorizada: “. . .et que venerat alienis ulnis deportata. gaudens et exiliens dominumque benedicens. suoque liberatori magnas gratiarum actiones referens. propriis gressibus rediit ad propria". Si bien es cierto que en $5^{8} 5^{a b}$ y $586 a$ se dice que la llevaron a poner ante el sepulcro del santo en unas andas y "pressa con vn dogal", no se utiliza la antítesis alienis ulnis deportata. . propriis gressibus rediit ad propria (esto reaparece, pero desaprovechado y sin relieve, en $58 \mathrm{gd}$ : "tornose ensus piedes para su uezindat"), y en cambio, probablemente a su observación de padecimientos reales (jcuántos enfermos habría visto llegar al monasterio "en andas", llevados por parientes y amigos, en busca de la milagrosa curación!) debemos versos como "sano la paralitica de la enfermedat, / mas non pudo tan luego uençer la flaquedat..." El mismo tipo de observaciones caracteriza la otra descripción del milagro de la paralítica:

Perdio ambos los piedes, non se podía mouer, / los dedos delas manos non los podia tender, / los oios tan turbiados que non podia ueer, / ninguno delos mjenbros non aujan su poder (292); que se fizo tan dura como vna madera $(291 d)$; Como auian los oios feos, la boca tuerta, / qualquiera delos braços tal como berga tuerta, / non podia del fogar salir fasta la puerta $(294 a-c)$; oras tornaua verde, oras tal como çera, / ca eran los dolores non de una manera $(297 c d)$.

Y hay que hacer notar, como rasgo artístico de gran madurez, que en este milagro la mención directa de la enfermedad ocurre en 3 ood, "para la paralitica salud li acabdar": antes sólo se la ha mencionado como "la enferma lazrada" (298a) y se han ido acumulando detalles descriptivos de su mal.

Hay, pues, en Santo Domingo también un mayor dominio de observación y de técnica en el trato de un determinado milagro, paralelo a la madurez de la arquitectura total de la composición. Ello no quiere decir que San Millán sea obra descuidada e informe, sino que entre las dos vidas ${ }^{42}$ podemos establecer un desenvolvimiento estético que corresponde a su cronología, dentro de las características que se han destacado en su arte de la narración, notablemente regular y sistemático ${ }^{43}$.

Frida Weber de Kurlat

Instituto de Literatura Española, Buenos Aires.

42 De propósito hemos limitado estas observaciones, sin incluir la Vida de Santa Oria; ésta, desde el punto de vista del contenido, pertenece a la literatura místico-visionaria, en cierto modo iniciada ya en Santo Domingo, donde dicho aspecto ocupa sólo las estrofas 229-244.

43 María Rosa Lida de Malkiel, "Notas para el texto de la Vida de Santa Oria', RPh, 10 (1956-57), 19-33. 